\title{
VARIA \\ Una capitulación relativa a una compañía crediticia de judíos de Huesca y Jaca
}

Eugenio Benedicto Gracia

Huesca

Estudio de la capitulación acordada en 1428 entre Abram Ambivag de Huesca y Judas Avingoyós de Jaca, para la resolución de los problemas suscitados por el cobro de ciertas deudas de la compañía crediticia que tienen formada. La lectura del documento pone de manifiesto algunas de las limitaciones de las fuentes notariales para el estudio del crédito judío debido a los pactos tácitos entre prestador y deudor que no siempre eran recogidos por escrito, y subraya la necesidad de reconsiderar determinados aspectos de su historia.

PaLABRAS Clave: historia de los judíos; Aragón: siglo xv; crédito judío; cultura notarial.

An Agreement between Jews of Huesca and Jaca Regarding a Credit Company. - This article analyzes a 1428 written agreement between Abram Ambivag of Huesca and Judas Avingoyos of Jaca to resolve problems arising from the collection of debts of their credit company. It highlights some of the limitations of notarial sources for the study of Jewish credit, as tacit agreements between lender and debtor were not always spelled out in writing, and it emphasizes the need to reconsider certain aspects of the history of Jewish moneylending.

KeYwords: Jewish History; Aragon; $15^{\text {th }}$ Century; Jewish Moneylending; Notarial Culture.

En los protocolos del Archivo Histórico Provincial de Huesca referidos a la aljama judía oscense es un tópico la mención a comandas de dinero y cereal concedidas a cristianos, moros y también a judíos, y lo mismo ocurre con la aljama de Jaca. Excepcional, sin embargo, es el hallazgo de un documento que trata de los problemas que afectaban en 1428 al cobro de ciertos créditos por una compañía establecida por tres judíos, uno de Huesca y dos de Jaca.

En efecto, Abram Ambivag, de Huesca, judío perteneciente a una familia arraigada en la ciudad, formaba una compañía junto a Judas Avingoyós, de Jaca, y al homónimo de este, «cosino mío, menor de días» ${ }^{1}$. Mientras que Abram apa-

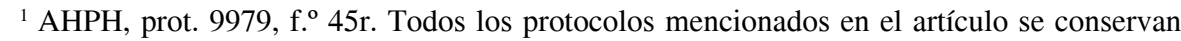
en este archivo. 
rece caracterizado como negociante y recaudador de impuestos, el caso de Judas es distinto. Aunque es probable que se dedicara además a otras ocupaciones, este último aparece mencionado como prestador, y por ese motivo está incluido en las listas de prestadores que juraban a comienzos de octubre de cada año de cumplir la regulación de no sobrepasar la tasa de interés permitida (si el 1 de octubre caía en una festividad judía, el juramento se retrasaba a un día hábil). Por los datos recogidos y que se muestran a continuación, vemos que aunque Judas parecía poseer menos relevancia económica, sin embargo llega a ejercer cargos ejecutivos en la aljama de Jaca. Del tercero de los participantes en la compañía, un menor homónimo del anterior, no he logrado reunir datos.

\section{Los actores}

El repaso de los protocolos conservados nos proporciona información fechada entre 1435 y 1447 acerca de Abram Ambivag. Con anterioridad a estas fechas, un documento de 1402 lo caracteriza como «aljamiante» en la venta de un censal $^{2}$. Por tal entendemos su inclusión en nóminas de individuos reunidos para determinar algún asunto de la comunidad judía, si bien es cierto que nunca figura desempeñando cargos ejecutivos de esta, como podían ser los de adelantado, clavario u otros. Pero sí aparece encargado de pagar ciertas deudas de la aljama en calidad de recaudador de sisas y alcabalas. Es decir, se trata de un individuo plenamente implicado en sus asuntos económicos. Carecemos de explicación al vacío documental en torno a su figura entre 1402 y 1435 , y puede deberse, bien a la pérdida de protocolos, o bien a que sus actividades se desarrollaban fuera de Huesca, como sucede, hasta donde tenemos datos, con su gerencia de la compañía crediticia, desarrollada con anterioridad a 1428 en el Campo de Jaca.

Aparece mencionado, además, como «aljamiante» en varias ocasiones; en una, para la designación de procurador de la aljama ${ }^{3}$. Su actividad en relación a esta se manifiesta en la frecuente mención como pagador de deudas y tributos: así, el 1-III-1436, paga al procurador de fray Ramón de Sinyan de 153 s[ueldos] $4 \mathrm{~d}$ [ineros] por el «alfferiz del Temple» ${ }^{4}$. E1 8-VIII-1437 paga en nombre de la aljama la «primicia» correspondiente a 1435 por importe de $50 \mathrm{~s}$ a los frailes de San Juan de la Peña ${ }^{5}$. En calidad de arrendador de la aljama, entrega el 30-IV-

${ }^{2}$ Prot. 11, f. $32 \mathrm{v}$.

${ }^{3}$ Prot. 192, f. ${ }^{\text { }}$ 67r-v (20-VII-1435). Otra mención como «aljamiante» en prot. 83, f. ${ }^{\circ} 154$ (7-V-1444).

${ }^{4}$ Prot. 9965 , f. $^{\text {7 }}$ r.

${ }^{5}$ Prot. 182 , f. ${ }^{\text {o }} 35 \mathrm{r}-\mathrm{v}$. 
1439 a Pedro d'Affa $250 \mathrm{~s}$ de «cens» perpetuo correspondiente a $1435^{6}$. Como «alcabalero» de la aljama paga el 9-III-1440 $112 \mathrm{~s}$ de «cens» perpetuo a Lop Sánchez de Ayneto ${ }^{7}$. El 21-V-1441, como arrendador de las sisas de la aljama, entrega $180 \mathrm{~s}$ de «cens» a Anthón de la Sierra, de La Perdiguera ${ }^{8}$. De nuevo, el 30-VII-1441, como arrendador de dichas sisas, entrega a Domingo Navarro 507 s, $8 \mathrm{~d}$ de los mil anuales que debía pagar la aljama ${ }^{9}$. El 10-I-1442, como arrendador de dichas sisas, entregaba a Symón Fornero $350 \mathrm{~s}$ como trehudo perpetuo ${ }^{10}$. Finalmente, el 9-IX-1446, como arrendador de las alcabalas de la aljama, entrega 195 s de «cens» a Sancho Bolea ${ }^{11}$.

Además, aparece mencionado con cierta frecuencia, bien como prestador de créditos; así, el 20-III-1435 presta 30 florines a un vecino de Arascués ${ }^{12}$, y el 30XII-1446, junto con Acach, a Tristán Ferrer ${ }^{13}$; o bien, como testigo de comandas en varias ocasiones: así, el 17-I-1436 ${ }^{14}$; de nuevo, el 9-VIII-1442 en una comanda de Abrayme Xuén ${ }^{15}$; el 12-XI-1445 en una comanda de Jucén Hadida ${ }^{16}$. El $12-\mathrm{VI}-1440$ en un «cens» de 350 s que recibe Symón Ferrer ${ }^{17}$.

Que fallece en 1447 se deduce de un protocolo donde se señala que,

Die predicto. Yo, Jentó Hambiuag, judío, heredero de Abrayme, padre mío, Baruc Hambiuag, hermano mío, quondam, haver recibido de vos, Johan Brita, vezino de Banastás, olim de Brecha, a una part CLXXX sueldos de Abrayme Hambiuag, padre mío, quondam, e a otra part cien e trenta sueldos que devía Acac Hambiuag, hermano mío. Renunciant a toda excepción e [ilegible], con aquesto quiero que las ditas cartas sean cancelladas [ilegible] e con aquesto vos absuelvo de [ilegible] frau. Testes: Miguel de Just e Simuel Hoín, judío Osce ${ }^{18}$.

\footnotetext{
${ }^{6}$ Prot. 6369, f. ${ }^{\circ} 15 v$.

${ }^{7}$ Prot. 81, f. $^{\circ} 59$ r.

${ }^{8}$ Prot. 217 , f. ${ }^{\circ} 113 v$.

${ }^{9}$ Prot. 217, f. ${ }^{\circ} 173 v$.

${ }^{10}$ Prot. 202, f. ${ }^{\circ} 8 \mathrm{v}$.

${ }^{11}$ Prot. 85, f. $291 \mathrm{v}-292$.

12 Prot. 287, f. ${ }^{\circ} 18$ r.

${ }^{13}$ Prot. 85, f. ${ }^{\circ} 6$.

${ }^{14}$ Prot. 79, f. ${ }^{\circ} 25$ r.

${ }^{15}$ Prot. 280, f. 280.

${ }^{16}$ Prot. 84, f. 391.

${ }^{17}$ Prot. 81, f. ${ }^{\circ} 136 v-137$ r.

${ }^{18}$ Prot. 190 (18-X-1447).
} 
El otro participante en la compañía es Judas Avingoyós, de Jaca, del que he logrado reunir noticias entre 1423 y 1447, en relación a sus actividades crediticias y al frente de la aljama. Así, comparece, junto a otros judíos, para en el juramento de no sobrepasar la tasa de interés permitida, en las siguientes fechas: $1-\mathrm{X}-1423^{19}, 1-\mathrm{X}-1426^{20}, 4-\mathrm{X}-1439^{21}, 9-\mathrm{IX}-1446^{22}$ y $10-\mathrm{X}-1447^{23}$. Es seguro que realiza el juramento otros años, pues el 30-XII-1444 es mencionado un préstamo suyo de 9 florines a Alfonso d'Stallo ${ }^{24}$.

Figura como adelantado de la aljama de Jaca el 6-XII-1430, donde se especifica que es hijo de Azerián, y como «aljamiante» se reúne para designar procurador de la aljama ${ }^{25}$. Años más tarde, el 27-IV-1438, figura de nuevo como «aljamiante», en la designación de A. Papur como procurador ${ }^{26}$.

Tenemos conocimiento de su familia por un documento de «compromiso» de 21-X-1454, en relación a un pleito de una deuda con sus herederos, y en la que se mencionan a varios familiares como Sol, Cetí, y «Reyna Veguer, muller de Judas Avingoyós, quondam» ${ }^{27}$.

\section{Una capitulación para la resolución de problemas suscitados en la compañía} crediticia

Tras la introducción habitual en todo acuerdo, el preámbulo señala que esta capitulación, firmada el 19 de abril de 1428, y que incluye 12 apartados, se ha acordado para «tirar los debates, pleytos e questiones que yeran e speravan seyer» entre los dos socios principales, para establecer las condiciones de cobro pendiente de 19 créditos - 46 deudores - contratados con anterioridad a 1428, y que oscilaban entre los $26 \mathrm{~s}$ declarados del más bajo y los $270 \mathrm{~s}$ del más alto, ascendiendo la cuya suma total a $1.785 \mathrm{~s}$, además de $2.701,49 \mathrm{kgs}$ de trigo. La capitulación incluye relación de los créditos contratados por habitantes del Campo de Jaca, incluyendo Ansó y Hecho, los valles de Tena y Serrablo, e incluso Sipán, al sur de la Sierra de Guara.

\footnotetext{
${ }^{19}$ Prot. 8672, f. ${ }^{\circ} 97 \mathrm{r}-99 \mathrm{v}$.

${ }^{20}$ Prot. 8673, f. ${ }^{\circ} 172 \mathrm{v}-175 \mathrm{r}$.

${ }^{21}$ Prot. 7952, f. ${ }^{\circ} 114 r-115 r$.

${ }^{22}$ Prot. 7959, f. ${ }^{\circ} 123 r-v$.

${ }^{23}$ Prot. 7970 , f. ${ }^{\circ} 102$ r-v.

${ }^{24}$ Prot. 8644, f. ${ }^{\circ} 53$ r-v.

${ }^{25}$ Prot. 8676, f. ${ }^{\circ} 117 \mathrm{v}$.

${ }^{26}$ Prot. 7951, f. $36 r-39 r$.

${ }^{27}$ Prot. 8821 , f. ${ }^{\circ} 62$ y ss.
} 
La capitulación determinaba que Abram Ambivag se encargaría de cobrar dichas deudas [2], lo que indirectamente apunta a que sería él (en nombre propio o como miembro de la compañía), quien habría concedido unos créditos cuya recuperación no parecía sencilla. Por ello, se cancelaban los compromisos previos firmados entre los agentes de la compañía [1] (a excepción de una comanda, ficticia como veremos, que se incluye al final [12]). La capitulación incluye una lista de los créditos que Abram debía cobrar o liquidar desde el 19 de abril de 1428, fecha de la firma, hasta San Martín de noviembre [3], teniendo Abram a partir de entonces plazo de un año (hasta San Martín de 1429) para terminar de ejecutar «a sus expensas» dichas deudas, salvo que los deudores firmaran nuevo débito [4]. Resulta interesante ver la naturalidad con la que se recoge la posibilidad de que las deudas se podían firmar nuevamente (frente a la alternativa de ejecución de bienes del deudor).

Al final, Abram debía rendir cuentas ante sus socios, repartiendo con ellos a partes iguales lo cobrado [7], descontando 60 florines que se reservaba para sus «aferes» (gastos) [6]. La relación de deudas es la siguiente:

\begin{tabular}{|c|c|c|c|}
\hline DEUDORES & LOCALIDAD & $\begin{array}{l}\text { CANTIDAD } \\
\text { PRESTADA }\end{array}$ & TRIGO PRESTADO \\
\hline $\begin{array}{l}\text { Johan Çalba } \\
\text { Sancho d'Orçandue } \\
\text { Xemenez Navarro } \\
\end{array}$ & $\begin{array}{c}\text { Jaca } \\
\text { Orcantué } \\
\text { Achahuas } \\
\end{array}$ & $90 \mathrm{~s}$. & \\
\hline $\begin{array}{l}\text { Xemeno d'Ayn } \\
\text { Gil de Layn }\end{array}$ & $\begin{array}{l}\text { Anayn } \\
\text { Novés }\end{array}$ & $100 \mathrm{~s}$. & \\
\hline $\begin{array}{l}\text { Domingo d'Urus } \\
\text { Rodrigo Villacampa } \\
\text { Martín de Bescós }\end{array}$ & $\begin{array}{c}\text { Urus } \\
\text { Espín } \\
\text { Bescós, Valle de Serrablo }\end{array}$ & $100 \mathrm{~s}$. & $\begin{array}{c}6 \text { robos } \\
2 \text { cuartales }\end{array}$ \\
\hline $\begin{array}{l}\text { García d'Allué } \\
\text { Sancho Palaço } \\
\text { Petro Laliena } \\
\end{array}$ & $\begin{array}{c}\begin{array}{c}\text { Allué } \\
“ \\
\text { Jaca }\end{array} \\
\end{array}$ & $50 \mathrm{~s}$. & 1 cahíz \\
\hline $\begin{array}{l}\text { Pero Martínez } \\
\text { Blasco Sampellayo } \\
\end{array}$ & $\begin{array}{c}\text { Hecho } \\
\text {. }\end{array}$ & $200 \mathrm{~s}$. & \\
\hline $\begin{array}{l}\text { Xemenen Palazín } \\
\text { Miguel de Santacruz }\end{array}$ & $\begin{array}{c}\text { Santa Cilia } \\
\text { “ }\end{array}$ & $26 \mathrm{~s}$. & \\
\hline $\begin{array}{l}\text { Martín Molinero } \\
\text { Martín de la Guarda }\end{array}$ & $\begin{array}{l}\text { Biduas } \\
\text { Gésera }\end{array}$ & $110 \mathrm{~s}$. & $\begin{array}{c}3 \text { robos } \\
3 \text { cuartales }\end{array}$ \\
\hline $\begin{array}{l}\text { Gonçalvo de Latrás } \\
\text { Sancho d'Allué }\end{array}$ & $\begin{array}{l}\text { Baranguá } \\
\text { Ansó }\end{array}$ & $112 \mathrm{~s}$. & 5 robos \\
\hline $\begin{array}{l}\text { Xemeno de Spenello } \\
\text { Miguel de Ayerbe }\end{array}$ & $\underset{\text { Martes }}{\text { “ }}$ & $64 \mathrm{~s}$. & 6 robos \\
\hline $\begin{array}{l}\text { Sancho Palacio, menor } \\
\text { Rodrigo Villacampa }\end{array}$ & $\begin{array}{l}\text { Sardás } \\
\text { Sipán }\end{array}$ & $50 \mathrm{~s}$. & 3 robos \\
\hline
\end{tabular}




\begin{tabular}{|c|c|c|c|}
\hline DEUDORES & LOCALIDAD & $\begin{array}{l}\text { CANTIDAD } \\
\text { PRESTADA }\end{array}$ & TRIGO PRESTADO \\
\hline $\begin{array}{l}\text { Fortunyo d'Allué } \\
\text { Xemeno de Latas } \\
\text { Juan d'Allué, al. Faranyate }\end{array}$ & $\begin{array}{l}\text { Allué } \\
\text { Sardás } \\
\text { Soas }\end{array}$ & $270 \mathrm{~s}$. & $\begin{array}{l}3 \text { cahíces } \\
3 \text { robos }\end{array}$ \\
\hline $\begin{array}{l}\text { Beltrán de Piedrafita, notario } \\
\text { Rodrigo Villacampa }\end{array}$ & $\begin{array}{l}\text { Soas } \\
\text { Espín }\end{array}$ & $65 \mathrm{~s}$. & 1 cahíz \\
\hline $\begin{array}{l}\text { Miguel de Bescasiella } \\
\text { García de Lovito }\end{array}$ & $\begin{array}{l}\text { Puente de Sabiñánigo } \\
\text { Allué }\end{array}$ & $62 \mathrm{~s}$. & 1 cahíz \\
\hline $\begin{array}{l}\text { Gonzalbo de Sarasa, clérigo } \\
\text { Martín de Pardiella, al Coreda } \\
\text { Johan d'Allué, scudero } \\
\text { Domingo Colón }\end{array}$ & $\begin{array}{c}\text { Osán } \\
\text { Soas } \\
\text { San Román } \\
\text { “ } \\
\text { “ }\end{array}$ & $74 \mathrm{~s}$. & 5 robos \\
\hline $\begin{array}{l}\text { Sancho d'Artasso } \\
\text { Martín Blascho }\end{array}$ & $\begin{array}{l}\text { Isus } \\
\text { Ena }\end{array}$ & $50 \mathrm{~s}$. & 5 robos \\
\hline $\begin{array}{l}\text { Blasco de Sim } \\
\text { Johan d'Allué, scudero } \\
\text { Domingo Colom }\end{array}$ & $\begin{array}{c}\text { Basa } \\
\text { San Román } \\
\text { “ }\end{array}$ & $62 \mathrm{~s}$. & 1 cahíz \\
\hline $\begin{array}{l}\text { Martín de Basa } \\
\text { Pero Amalt }\end{array}$ & $\begin{array}{l}\text { Fanliello } \\
\text { Fenés }\end{array}$ & $150 \mathrm{~s}$. & 2,5 cahíces \\
\hline $\begin{array}{l}\text { Xemeno de Muro } \\
\text { Pedro de Agüero } \\
\text { Miguel de Latas }\end{array}$ & $\begin{array}{c}\text { Barós } \\
\text { ، } \\
\text { “ } \\
\end{array}$ & $100 \mathrm{~s}$. & $\begin{array}{l}5 \text { robos } \\
2 \text { cuartales }\end{array}$ \\
\hline $\begin{array}{l}\text { García d'Iéspola } \\
\text { Domingo Besarán }\end{array}$ & $\begin{array}{l}\text { Castiellorés } \\
\text { Biduas }\end{array}$ & $40 \mathrm{~s}$. & 1 cahíz \\
\hline
\end{tabular}

Esta nómina detalla el monto del débito - créditos mixtos que incluyen cereal -, pero no el interés aplicado - que quedaría oculto en el capital prestado -, ni tampoco las condiciones del préstamo. Una forma normal del préstamo de cereal era cobrar el interés en el momento de la cosecha recibiendo el cincuenta por cién de lo cosechado.

Abram debía dar cuenta a Judas de lo cobrado, tomando para sí los 60 florines acordados, y en caso de que no pudiera cobrar algunas cartas, haría nuevas cartas de deuda de las que Judas elegiría las que mejor le pareciera [5]

Se determina que Abram jurara y firmara los presentes capítulos, reiterando la forma de reparto de los beneficios. No obstante, se recuerda a Abram que no podría hacer por su cuenta ninguna «composición» con los deudores. Si eso sucediera y «desfalcás» cosa alguna en el beneficio, la pérdida correría por su cuenta. Sólo en caso de que Judas tuviera conocimiento de esa «composición», no tendría Abram que pagar la pérdida, sino que esta se repartiría entre ambos [8]. Está claro que en el pasado Abram había obrado según su criterio o interés 
personal y en estas nuevas capitulaciones, creo yo, los Avingoyós (mayor y menor) van a controlar con mayor rigor las actuaciones de aquel. Este capítulo nos indica que, al margen de la literalidad de la comanda, acreedor y deudor podían «componer» condiciones especiales que el documento no especifica, como podía ser el verdadero interés a cobrar, y esto resulta enormemente interesante como reflejo de pactos tácitos que no quedaban reflejados por escrito.

A continuación, se señala que si algún deudor mostrara albarán o carta partida («tallida») que cobrara Abram dichos débitos mostrando las cartas a Judas, de manera que quedara patente haber pasado dichas cartas partidas ante notario para saber que el pago se había llevado efectivamente a cabo. Con ello, se trataba de averiguar si había habido bienes como avales. De esta manera, Judas no podría demandar nada a Abram, y si se hubiera cobrado la deuda se procedería al reparto convenido [9].

Abram exigía que Judas menor le diera una procuración, y en caso de que estuviera fuera de Jaca, que la hiciera en su nombre Judas mayor, ya que tenían poderes mutuos para permitir a Abram gestionar cuanto necesite con los deudores dejando claro que si la procuración fuera rechazada y no se pudiera cobrar, los Avingoyós pagarían los 60 florines y la mitad del resto de la cuantía [10]. En ningún caso podrían los Avingoyós inmiscuirse en trámite alguno con los deudores, y si lo hicieran quedaría anulada su actuación y tendrían que restituir lo cobrado [11].

En el último capítulo, uno de los más reveladores, se menciona una carta de comanda (realizada el 15 de julio de 1426, acto en el que había estado presente un tal Sentó, actuando como notario Gil de Villanúa, de Jaca ${ }^{28}$ ), por la que Judas había aparentemente prestado 65 florines a Abram. Judas se había visto obligado a hacer esta «contracarta» por razones de «seguridat», entiéndase por falta de confianza. En caso de que Abram cumpliera los capítulos citados, no demandaría Judas su cobro, que sólo se produciría en caso de incumplimiento [12]. A continuación, añaden Abram y Judas sus firmas en hebreo en ratificación de estos capítulos.

El documento finaliza con una larga relación de los compromisos adquiridos según «Ley de jodíos», con las características renuncias a salvedades de cualquier clase que pudieran beneficiar a los componentes de la capitulación y, por extensión, a Judas menor que queda implicado en todas las cláusulas del negocio $^{29}$.

\footnotetext{
${ }^{28}$ Prot. 9979, f. ${ }^{\circ} 45$ r.

${ }^{29}$ Agradezco a los Srs. Jaume Riera i Sans y Javier Castaño por sus comentarios en relación a la interpretación de este documento.
} 
1428, abril 19, Jaca

Capitulación acordada entre Abram Ambivag, de Huesca, y Judas Avingoyós, de Jaca, en su nombre y en el de su familiar homónimo, para resolver los problemas del cobro de la compañía de créditos que tienen formada ${ }^{30}$.

AHPH, prot. 9979, f. 31 r-42r, notario Ximenez de Aragüés.

Sía a todos maniffiesto, anno a Nativitate Domini millésimo CCCC XXVIII, día que se intitulava XVIIII del mes de abril, en la ciudat de Jacca, en presencia de mí, notario, e de los testimonios dius scriptos, fueron personalment constituídos Abram Ambiuag, judío de la ciudat de Huesca, de la una part, e Judas Avingoyós, mayor de días, judío de la ciudat de Jacca, en nombre suyo propio e assí como procurador de Judas Avingoyós, menor de dias, judío habitant en la dita ciudat de Jacca, de la otra. Constituydo con carta pública de procuración, feita en la ciudat de Jacca, a XII dias del mes de julio, anno a Nativitate Domini M $^{\circ}$ CCCC XXVI, por Tomás d'Orant, habitant en la ciudat de Çaragoça, e por autoridat real notario público por todo el regno d'Aragón; ${ }_{31 v}$ los quales en los ditos nombres, e cada uno d'ellos, daron en poder en manos de mí, dicto e inffrascripto notario ciertos capitoles de ciertas avinensas e composiciones entre ellos firmes. El tenor de los quales capitoles yes según se sigue:

${ }_{32 \mathrm{r}}$ Por tirar los debates, pleytos e questiones que yeran, e speravan seyer entre Abram Ambiuag, judío habitant en la ciutat de Huesca, de la una part, e Judas Abingoyós, mayor de dias, e Judas Avingoyós, menor de días, judíos de la ciudat de Jacca, de la otra, son feytos, concordados et firmados los pactos, convenios e capitoles siguientes:

[1] Primo, yes seydo, concordado e por pacto special et firme atorgado, que todas e qualesquiera cartas de procuraciones, compromisos, sentencias e qualesquiera pactos e convenios entro al día present, feytos entre las ditas partes conjuntament o de partida, sían havidas por cassos nullos, iratos e de ninguna efficacia o valor, assí como si feytos o testificados no fuessen.

[2] ${ }_{32 \mathrm{v}}$ Item yes seydo, concordado e en pacto deducco, que el dito Abram Ambiuag cobre e sía tenido fazer toda su diligencia de cobrar las deudas que se siguen:

Primerament de Johan Çalba, habitant en la ciudat de Jacca, e de Sancho d'Orçandue, habitant en el lugar de Orçandue, e de Xemenez Navarro, habitant en el lugar de Achahuas: novanta sueldos dineros jaqueses, con sus ganancias.

Item de Xemeno d'Ayn, habitant en el lugar de Anayn, e de Gil de Layn, habitant en el lugar de Novés: cient sueldos dineros jaqueses, con sus ganancias.

Item de Domingo d'Urus, habitant en el lugar de Urus, de Rodrigo Villacampa, habitant en el lugar d'Spin, et de Martín de Bescós, habitant en el lugar de Bescós, de la Val de Serravllo: ${ }_{33 \mathrm{r}}$ cient sueldos dineros jaqueses et seys rovas e dos quartales de trigo, mesura de Jacca, con sus ganancias.

Item de García d'Allué et de Sancho Palaço, yerno suyo, habitantes en el lugar d'Allué e de Petro Laliena, habitant en la ciudat de Jacca: cinquanta sueldos dineros jaqueses e hun kaffiz de trigo, mesura de Jacca, con sus ganancias.

${ }^{30}$ No he considerado pertinente reflejar en la transcripción los casos de doble consonante inicial (fflorines, ffaga, ffeytas, etc.). 
Item de Pero Martínez e Blasco Sampellayo, habitantes en la villa d'Echo: dozientos sueldos dineros jaqueses, con sus ganancias.

Item de Xemenen Palazín et Miguel de Santacruz, habitantes en el lugar de Santa Çilia: XXVI sueldos dineros jaqueses, con sus ganancias.

Item de Martín Molinero, habitant en el lugar de Biduas, e de Martín ${ }_{33 \mathrm{v}}$ de la Guarda, habitant en el lugar de Gésesa: CX sueldos dineros jaqueses e III rovas, tres quartales de trigo, mesura de Jacca, con sus ganancias.

Item de Gonçalvo de Latrás, habitant en el lugar de Baranguá, e de Sancho d'Allué, habitant en el lugar de Ansó: CXII sueldos dineros jaqueses e $\mathrm{V}^{\mathbf{o}}$ robas de trigo, mesura de Jacca, con sus ganancias.

Item de Xemeno de Spenello e de Miguel de Ayerbe, habitantes en el lugar de Martes: LXIIII ${ }^{\circ}$ sueldos dineros jaqueses e VI robas de trigo, mesura de Jacca, con sus ganancias.

Item de Sancho Palacio, menor, habitante en el lugar de Sardas, e de Rodrigo Villacampa, habitante en el lugar de Sipán: L sueldos ${ }_{34 \mathrm{r}}$ dineros jaqueses e tres rovas de trigo, mesura de Jacca, con sus ganancias.

Item de Fortunyo d'Allué, habitante en el lugar de Allué e de Xemeno de Latas, habitante en el lugar de Sardas, e de Juan d'Allué, alias Faranyate, habitante en el lugar de Soas: CCos e LXX sueldos dineros jaqueses e tres kaffizes e III robas de trigo, mesura de Jacca, con sus ganancias.

Item de Beltrán de Pietrafita, notario, habitant en el lugar de Soas, e de Rodrigo Villacampa, habitant en el lugar de Spin: LXV sueldos dineros jaqueses et hun kaffiz de trigo, con sus ganancias.

Item de Miguel de Bescasiella, habitant en la casa del Puent de Savinyanego, e García de Lovito, habitant en el lugar d'Allué: LXII sueldos ${ }_{34 \mathrm{v}}$ dineros jaqueses e hun kaffiz de trigo, mesura de Jacca, con sus ganancias.

Item de D. Gonzalbo de Sarasa, clérigo, rector d'Osán, e de Martín de Pardiella, alias Coreda, habitant en el lugar de Soas; de Johan d'Allyué, scudero, e Domingo Colom, habitantes en el lugar de Santa Román: LXXIIII sueldos dineros jaqueses e $\mathrm{V}^{\mathrm{o}}$ rovas de trigo, mesura de Jacca, con sus ganancias.

Item de Sancho d'Artasso, habitant en el lugar d'Isus, e Martín Blascho, habitant en el lugar d'Ena: $\mathrm{L}$ sueldos dineros jaqueses, e $\mathrm{V}^{\mathbf{o}}$ rovas de trigo, mesura de Jacca, con sus ganancias.

Item de Blascho de Sim, habitant en el lugar de Sim de Basa, de Johan d'Allué, scudero, e Domingo ${ }_{35 r}$ Colom, habitantes en el lugar de Santta Román: LXII sueldos dineros jaqueses e hun kaffiz de trigo, mesura de Jacca, con sus ganancias.

Item de Martín de Basa, habitant en el lugar de Fanlliello, e de Pero Amalt, habitant en el lugar de Fenés: CL sueldos dineros jaqueses et dos kafizes e medio de trigo, mesura de Jacca, con sus ganancias.

Item de Xemeno de Muro, de Pedro d'Agüero e Miguel de Latas, habitantes en el lugar de Barós: $\mathrm{C}$ sueldos dineros jaqueses, $\mathrm{V}$ rovas, II quartales de trigo, mesura de Jacca, con sus ganancias. 
Item de García d'Iéspola, habitant en el lugar de Castiellorés, e de Domingo Besarán, habitant en el lugar de Biduas: quaranta sueldos dineros jaqueses e hun kaffiz de trigo, mesura de Jacca, con sus ganancias.

[3] ${ }_{35 \mathrm{v}}$ Item yes seydo, concordado e composado e por pacto special hauido, que el dito Abram faga executar todos los ditos deudores, entro al día e fiesta de Sant Martín del mes de noviembre, primero vinient del present e infrascripto annyo que se conta millésimo CCCC XXVIII.

[4] Item yes seydo, concordado, e por pacto havido entre las ditas parte que, feytas las ditas execuciones, el dito Abram d'allí avant sía e finque tenido fazer continuar aquellos a sus expensas et fazer toda diligencia que las ditas execuciones se acaben de manera que se cobren los ditos deudos o se firmen nuevament e aquesto entro al día e fiesta de Sant Martín del mes de noviembre del anyo de mil CCCCos XXVIIII, ${ }_{36 r}$ finado el dito término, el sobredito Abram sía tenido dar conto al dito Judas e partir con él aquello que cobrará, receuido pora sí LX florines, con los quales diuso se faze mención, e darle de continent su part realment e de feyto. Pero si alguno aquí será mandada fazer la execución, mostrará albarán; que las expenssas que se farán, sían tenidas pagar los ditos Abram Ambiuag e Judas por yguales partes.

[5] Fue encara concordado que, caso que dineros non podies cobrar, el dito Ambiuag que dando su part en cartas nuevament firmadas al dito Judas, aquellas empero que él se sleyría que el dito Judas sía tenido prender su part en las ditas cartas renovadas.

[6] Item yes seydo, concordado, e por pacto special ${ }_{36 \mathrm{v}}$ firme e irrevocable firmado, que de los primeros dineros que sallirán de los ditos deudos, se prenga e retienga en sí el dito Abram Ambiuag, por algunas expensas que ha feytas et por los traballos que sostenrá en cobrar aquellos LX florines d'oro d'Aragón.

[7] Item yes seydo, concordado, e por special pacto havido entre las ditas partes, que saccados los ditos LX florines, la restant quantía et trigo que se cobrará, sía común de los ditos Abram Ambiuag e Judas Avingoyós, mayor de días, e aquella e aquell partan por yguales partes.

[8] Item yes seydo, concordado, que el dito Abram, el día que los presentes capitoles serán firmados, sía tenido jurar e jure sobre los X mandamientos de la Ley de Moysén, que se habrá ${ }_{37 \mathrm{r}}$ bien e lealment en cobrar los ditos deudos et saccados los ditos LX florines, la resta adverá a buena, leal e verdadera partición con el dito Judas, e que no fará ni pueda fazer composición alguna con los ditos deudores o alguno d'ellos, por la qual composición se perdiés o defalcás cosa alguna de la principal suert. E si lo fazia, que todo aquello que se defalcará e perderá de la suert principal se pueda al dito Abram Ambiuag, e de la mitat de todo aquello que habrá feyto contra o se lexará perder por la dita composición sía tenido reintegrar, responder, e pagar al dito Judas el sobredito Biuag de lo suyo propio, sino yes que la dita composición fiziés con voluntat del dito Judas e feyta la dita partición realment le pagará e librará ${ }_{37 \mathrm{v}}$ su part segunt dito yes.

[9] Item yes seydo concordado que caso que algunos de los ditos deudores mostrassen albaranes de los deudos o cartas tallidas, que cobrando el dito Ambiuag los albaranes e las ditas cartas tallyadas, empero que aquellos e aquellas muestre al dito Judas o mostrar faga legítimament por los originales o copia fe fazient, en la qual se demuestre que el notario que fará la copia vido la carta tallyada, por razón de tales cartas que así se demostrarán seyer pagadas o no haver hi trobado bienes que no pueda el dito Judas cosa alguna demandar al 
dito Ambiuag. Et en aquel caso, sía tenido el dito Ambiuag tales ${ }_{38 \mathrm{r}}$ cartas, las quales pagadas se trobarán a contraduzir porque aquellos partan segunt que de suso yes concordado, o tallen aquellos entramos concordes o ende pueda fazer a su voluntat cada uno de su part.

[10] Item yes concordado e en pacto deducco, que'l dito Judas Avingoyós, menor, sía tenido fazer nuevament una procuración al dito Abram Ambiuag o si el dito Judas, menor, no yes en ciudat, que'l dito Judas, mayor de días, qui yes su procurador, e ha bastant poder, le faga substitución, en la qual li dé pleno e bastant poder a demandar, hauer, recebir e cobrar todos los ditos deudos et fazer albaranes e a pleytos assí bastantement como necessario será, e por el dito Abram, sea demandado et jurarán que la dita substitución no revocará et si el dito Judas, menor, absent el dito Judas, mayor, así como procurador del dito Judas ${ }_{38 v}$ et en su nombre propio se obligará que la dita substitución no revocará en tiempo alguno et caso que se revocás prometerá e se obligará el dito Judas e promiso e se obligó e juró en los ditos nombres que, si por causa de revoca la dita procuración, se empacharán de cobrar los ditos deudos o partida de aquellos de los ditos LX florines et la mitat de la restant quantía, satisfará et pagará de sus bienes e del dito su principal al dito Ambiuag.

[11] Et noresmenos fue concordado e por special pacto firmado, que los ditos Judas Avingoyós, mayor, e Judas Avingoyós, menor, ni alguno d'ellos no se puedan d'aquí avant entremeter en demandar los ditos deudos o partida de aquellos, ni fazer albarán ${ }_{39 \mathrm{r}} \mathrm{o}$ albaranes ni cosa alguna fazer empachant el cobrar de los ditos deudos et si lo fazían que todo aquello fues casso, irato e de ninguna efficacia o valor e fuessen e sían tenidos a restitución de las ditas quantías, de las quales albarán o albaranes farán d'aquí avant en ninguna manera la paga e solución d'aquellas e cada una d'ellas empachantes.

[12] Item por tal que la meytat de los ditos deudos sacados los ditos LX florines se han a partir entre los ditos Abram e Judas Avingoyós. Yes seído, concordado e en pacto havido, que por seguridat del dito Judas, aquella carta de comanda, testificada por Gil de Villanúa, notario, por la qual consta el dito Abram Ambiuag seyer tenido al dito Judas en LXV florines d'oro se sté ${ }_{39 \mathrm{v}}$ et finque en la forma que yes feyta e testificada pero que el dito Judas sía tenido fazer vna contracarta al dito Abram Ambiuag que, teniendo e seruando el dito Ambiuag los pactos sobreditos, no pueda demandar la dita comanda, pero si no la seruara [sic] aquellos e qualesquier d'ellyos que en aquel caso pueda demandar la dita comanda, bien assí como havría podido ante et por aquello ninguna prendición no li sía engendrado e d'aquesto atorgue el dito Judas la dita carta assi bastantment como necessario será.

אברהם ביבאג' יהודה גויוש

${ }_{40 \mathrm{r}}$ Et dados e observados los ditos capitoles, los ditos Abram Ambiuag, en su propio nombre, e el dito Judas, en los nombres propio e procuratorio ante ditos, de continent juroron sobre los X Mandamientos de la Ley de Moysén de tener e conplir e firmement observar todas e cada unas cosas en los ditos capitoles contenidas, e fazer servir aquellas al dito Judas segunt la contenerá e tenor de los capitoles sobreditos.

Et prometieron e se obligaron los ditos Abram e Judas en los nombres sobreditos e cada uno d'ellos con quinyán complido según Ley de Jodíos, ad invycem tener, complir e ob-

${ }^{31}$ Firmas autógrafas: «Abraham Bibag, Yehudá Ben Goyós». 
seruar todas e cada unas cosas en los ditos capitoles expresadas e qualquiere d'ellas e contra aquellas o alguna d'ellas no venir en tiempo alguno. Et prometieron el dito Judas, ${ }_{40 \mathrm{v}}$ menor, yera absent, el dito Judas Avingoyós, mayor, no partiéndose de la obligación sobredita en su propio nombre, se obligó que el dito Judas no venirá contra las cosas contenidas en los ditos capitoles o alguna d'ellas. E si lo fazía, el dito Judas, mayor, promisó e se obligó e quiso e expressament consintió e le plazía con quinyán complido, seyer tenido a observación de todo aquello que el dito Judas yera e yes tenido, bien assí como si a mí fuese expreso e largament recitado, et aquello quiso haver por expresso, recitado e reyterado, bien assí como si de palabra a palabra aquí fuesse recitado, reyterado, scripto e notado, e ad aquellos bienes suyos seyer tenidos e obligados. E assí el dito Abram ${ }_{41 \mathrm{r}}$ Ambiuag como el dito Judas, mayor, en los nombres sobreditos e cada uno d'ellos conjuntament e de partida a todo lo sobredito, tener, complir e obseruar, obligaron sí mismos personalment e todos sus bienes mobles e sedientes, havidos e por haver, en todo lugar et el dito Judas obligó la persona e bienes del dito principal, mobles e sitios, hauidos e por hauer, en qualquiere manera et prometieron e se obligoron ad invycem con quinyán complido en los ditos nombres e cada uno d'ellos por la dita razón, haver, dar, mostrar e assignar bienes suyos e del dito Judas su principal mobles propios quitos e desenbargados a complimiento de todo lo sobredito.

Et renuncioron por todas e cada unas cosas sobreditas los ditos Abram e Judas e cada uno d'ellos, en los nombres sobreditos, e qualesquiere d'ellos sus judges e de cada uno d'ellos ${ }_{41 v}$ ordinarios e locales. Et sozmetiéronse con todos sus bienes a la jurisdicción, coherción e compulssa de aquell judge o judges de la una part a l'otra, mas convenirse querrán.

E renuncioron por todo lo sobredito, los ditos Abram e Judas, en los ditos nombres e qualesquiere d'ellos generalment a todas e cada unas excepciones, dilaciones, allegaciones e deffenssiones de fuero, uso, costunbre del Regno, razón scripta e Ley de jodíos, que al contravenient o contravenientes podiessen valer e ayudar, que no le valyrán ni ayudará e a la otra part nozerá e que no li[ilegible] contrasten en alguna manera.

No obstan aquella ley o dreyto dizient que general renunciación ${ }_{42 \mathrm{r}}$ no val si el renunciant no exprime o no yes certificado de aquello, ni renuncian a la general ley e dreyto de todos sus dreytos e del dito Judas su principal, bien certifficados, dizientes que renunciavan e expresament renuncioron. Esto fue feito, anyo, mes, día e lugar sobreditos. Presentes: maestre Pere Martín, físigo, e Mayl Alcalá e Sentó Almosnín, menor de días, judíos habitantes en la dita ciudat de Jacca, testimonios ad aquesto clamados e rogados.

Recibido: 03/02/2010

Aceptado: 04/10/2010 